\title{
Breves Considerações sobre as Especificidades daS Normas Sanitárias Internacionais de Forma Geral e em Particular do Regulamento Sanitário InTERnacional
}

\author{
SHORT CONSIDERATIONS ABOUT THE SPECIFITIES OF \\ INTERNATIONAL SANITARY RULES AND THE \\ INTERNATIONAL HEALTH REGULATION
}

E. Mondielli(*)

\section{RESUMO}

A partir da verificação de que o Direito Internacional Sanitário deixou de ser uma área derivada do Direito Administrativo Internacional, tornandose um Direito formado pelas áreas administrativa, econômica e social, conclui-se que ele é tanto uma parte do Direito Internacional Econômico, como do Direito Internacional do Desenvolvimento. O objetivo deste trabalho é o de apresentar o que é o Direito Internacional da Saúde e qual sua influência no Direito francês, tratando, especialmente, do Regulamento Sanitário Internacional.

\section{Palavras-chave}

Direito Sanitário Internacional; França; Organização Mundial da Saúde; Regulamento Sanitário Internacional.

\section{ABSTRACT}

Starting from the verification that International Health Law is no more a derived area of the International Administrative Law, becoming a right that mixes administrative, economical and social Law, it is concluded that it is as

(*) Diretor Adjunto do CERDES (Centro de Estudos e Pesquisas em Direito Sanitário Europeu) de Nantes. E-mail: <eric.mondielli@wanadoo.fr>. 
much as a part of the Economical International Law as of the International Right of the Development. This work has as objective to demonstrate what is the International Health Law and its influences in French Law, approaching, especially, the International Health Regulation.

\section{Key words}

France; International Health Law; International Health Regulation; World Health Organization.

\section{INTRODUÇÃO}

Quanto caminho percorrido pelo Direito Internacional Sanitário desde 1930, quando a doutrina o considerava uma área derivada do Direito Administrativo Internacional(1). Segundo Michel Bélanger, essa área do Direito internacional público é fundamentalmente mista, pois engloba o Direito Administrativo, o Econômico e o Social(2). O Direito Internacional da Saúde aparece, assim, como uma parte do Direito Internacional Econômico e do Direito Internacional do Desenvolvimento. O Direito Internacional da Saúde e o Direito Comunitário da Saúde, disciplinas pouco ensinadas nas faculdades, são áreas do Direito, relativamente, novas e desconhecidas pelos internacionalistas, enquanto as preocupações sanitárias, em nível internacional e regional, aumentam e ocupam um grande espaço a cada dia (ver, por exemplo, a questão do acesso aos medicamentos e aos tratamentos, principalmente na luta contra SIDA). No quadro de reflexão sobre "as normas sanitárias internacionais"(3), parece essencial atentar à questão das especificidades e do caráter dessas normas e também daquelas regionais. O modesto objetivo desta contribuição é, de um lado, relembrar o que é o Direito Internacional da Saúde, deixando de lado o que não é, tentando salientar seus traços principais e, por outro lado, colocar em perspectiva, apoiando-se em exemplos concretos, de que maneira esse Direito exerce uma influência no direito francês.

Para começar, parece necessário dar uma definição sumária do que é o Direito Internacional da Saúde (DIS), uma área Direito Internacional Público que tem por objetivo estudar as regras jurídicas aplicáveis pela

(1) VITTA, Cino. Le droit sanitaire international. RCADI, v. 33, p. 549, 1930.

(2) BÉLANGER, M. Le droit international de la santé. Paris: PUF, 1997. p. 8. (Col. QSJ n. 3234).

(3) Este artigo é uma sintese de nossa comunicação feita por ocasiāo do seminário organizado pelo CRUARAP consagrado ao tema "as normas sanitárias internacionais", em dezembro de 2003 (seminário de pesquisa organizado pelo professor A. Fenet - Faculdade de Direito de Nantes -, com a participação do professor M. Bélanger - Faculdade de Direito de Bordeaux-Montesquieu). 
comunidade internacional às ações de saúde, sendo que essas regras são principalmente produzidas pelas organizações internacionais e regionais. O principal interesse dessa definição é evidenciar que a produção normativa internacional no setor de saúde é, essencialmente, fruto de diversas ações de organizações internacionais. Todavia, por causa da grande diversificação de fontes normativas internacionais e sua grande heterogeneidade ${ }^{(4)}$, bem como para limitar nosso propósito, a reflexão apenas irá referir-se à legislação da Organização Mundial da Saúde (OMS). Esta escolha não é arbitrária, pois, em nivel internacional, a OMS é a principal autoridade diretiva e coordenadora na área da saúde e dos trabalhos de caráter internacional $^{(5)}$, e ainda a única organização com objetivo sanitário.

O DIS é caracterizado por uma institucionalização muito forte. Tratando das relações entre saúde e direitos do cidadão, as organizações internacionais contribuem amplamente para a evolução do direito à saúde, tanto no plano nacional, como no internacional(6). É quase banal sublinhar que freqüentemente o direito à saúde, em nível nacional, deve ser completado pela elaboração de um conjunto de regras e normas em nível internacional ou regional. Esse trabalho é na realidade assumido por um grande número de instituições (intergovernamentais e não governamentais). Desde o fim do segundo conflito mundial, a introdução e a incidências das atividades internacionais aumentaram muito, bem como o papel desempenhado pelo $\mathrm{Di}$ reito Sanitário. Devemos salientar que, ao lado da OMS, um grande número de organizações internacionais exerce competências de ordem sanitária (ONU, UNESCO, OIT, FAO etc.). O trabalho do DIS é o resultado das atividades delas. Se os Estados participam da elaboração do DIS diretamente, através da edição de normas sanitárias, a maior parte das vezes em caráter bilateral ou pouco multilateral, é no âmbito das organizações intergovernamentais que a participação deles na elaboração é mais ativa e determinante, na medida em que são os Estados que em última instância decidem adotar ou não os textos propostos pelas instituições internacionais.

A doutrina teve a oportunidade de demonstrar que o Direito Internacional da Saúde está dividido entre duas tendências institucionais antagonistas (na realidade influenciado por um movimento institucional em dobro), ou seja, a busca da centralização e a necessidade da descentralização. É preciso deixar claro que a idéia de centralização sanitária internacional(7) não teve

(4) Quanto a esses aspectos, BÉLANGER, M. Droit international de la santé. Revista de Québec de Direito Internacional, v. 2, p. 11-18, 1985; MONDIELLI, E. La prise em compte des normes OMS par lê droit français. RGDM, n. 1, p. 87-116; FLUSS, Sev. S. The development of national legislation in Europe the contribution of international Organizations, European. Journal of Health Law, n. 2, p. 193 et S., 1995.

(5) Cf. Constituição da OMS art. 2, a.

(6) ABBING, V.H. Roscam. La santé, droits de l'homme et droit de la santé: vers une internationalisation, en particulier dans le contexte européen. RILS, v. 49, n. 1, p. 99 e s., 1998.

(7) BÉLANGER, M. Le droit international de la santé, cit., v. principalmente as considerações sobre os limites da centralização sanitária internacional, p. 19 e s. 
sucesso na quase totalidade. A OMS, única organização com objetivo sanitário (que sucedeu o Escritório Internacional de Higiene Pública e a Organização de Higiene da Liga das Nações), viu, desde que nasceu, sua atividade sendo disputada e limitada pelas competências sanitárias exercidas pelas outras organizações do sistema das Nações Unidas.

O aumento das atividades transfronteiriças e do comércio internacional, além da conseqüência da concorrência, tem um impacto sobre inúmeros tratamentos e direitos conexos do homem. O interesse comum dos Estados e a necessidade imperiosa de fixar regras e linhas diretivas internacionais, por conta dos movimentos transfronteiriços, permitem explicar o lugar cada vez mais crescente ocupado pelo DIS e, conseqüentemente, o apoio dado, pelas organizações internacionais, para o desenvolvimento da política sanitária de vários países e a elaboração de regras e normas internacionais e supranacionais com força obrigatória. O Direito Sanitário torna-se cada vez mais tributário da internacionalização e da mundialização do comércio e necessita que as organizações internacionais, atores e autores do DIS, façam pleno uso de suas competências para impedir que as considerações de ordem econômica tomem a dianteira sobre os interesses da saúde. $O$ lugar ocupado pelo DIS leva, então, a questionamentos sobre a especificidade das normas sanitárias internacionais. Depois de termos invocado, num plano geral, a questão sobre a especificidade das normas sanitárias internacionais, daremos uma atenção particular a um dos aspectos mais originais da Legislação Sanitária Internacional (LSI), a saber, o Regulamento Sanitário Internacional.

\section{I - A ESPECIFICIDADE DAS NORMAS SANITÁRIAS INTERNACIONAIS ${ }^{(8)}$}

Falar da especificidade das normas sanitárias internacionais, é de fato pôr em perspectiva a singularidade (ou as singularidades destas normas) relacionada ao seu caráter. Tradicionalmente distinguimos o Direito de subordinação e o Direito de cooperação. O Direito interno aparece como Direito de subordinação (uma só ordem jurídica e sujeitos subordinados ao poder do Estado), enquanto o Direito internacional público aparece como um Direito de cooperação elaborado em conjunto pelos Estados soberanos diretamente (ou indiretamente, no seio das organizações internacionais) na ordem internacional. Este Direito não conhece legislador, juiz ou sanção obrigatória, além do consentimento das nações em questão. As normas sanitárias internacionais não pertencem ao direito de subordinação na medida que elas são desenvolvidas no quadro da sociedade internacional. Todavia, elas não parecem participar exclusivamente do direito de coor-

(8) Preferimos usar o termo "normas sanitárias internacionais" em vez de falar de "norma sanitária internacional" por causa da grande variedade de normas do Direito Internacional da Saúde. 
denação uma vez que visam afirmar um direito de proteção à saúde como direito da pessoa humana em nivel internacional. As normas sanitárias internacionais são elaboradas em função do interesse das pessoas. Entretanto, é preciso sublinhar (a história do Direito Internacional da Saúde existe para lembrá-lo( $\left.{ }^{(9)}\right)$ que, mais freqüentemente, são as preocupações ligadas ao problema crescente de eliminar os obstáculos ao comércio e às exportações, bem como a vontade de se proteger contra as "doenças exóticas", do que as preocupações humanitárias que estão na origem das ações públicas voltadas à área sanitária (é preciso lembrar também que o desejo de erradicação de doenças transmissiveis foi a principal preocupação das nações européias e que os primeiros textos de "legislação sanitária internacional" tinham um objetivo limitado: a luta contra as doenças contagiosas).

Destacar a especificidade do Direito Internacional da Saúde, bem como das normas que o compõem, não significa que não possa haver conexões com outras áreas do Direito internacional público, mas simplesmente que ele está estruturado em um núcleo rígido com princípios e regras que o tornam singular. Portanto, é preciso identificar as características dessa área do Direito internacional, considerando que estas características são volúveis em função das mudanças políticas e jurídicas da sociedade internacional e dos desenvolvimentos científicos e tecnológicos. Além disso, as áreas existentes ou emergentes, que têm uma dimensão sanitária, podem passar por evoluções que farão surgir áreas do Direito internacional com caráter hegemônico, ou pelo menos como se estivessem exercendo um poder atrativo sobre outros setores disciplinares.

\section{A - O DIS, uma área à parte do Direito internacional público por inteiro}

Esta afirmação não está apoiada em simples pretensões doutrinárias. $O$ fato de que diversas organizações internacionais terem competências sanitárias em nivel internacional e regional(10), bem como de que exista uma

(9) Quanto à história do DIS e da saúde pública, v. principalmente HOWARD-JONES, N. Les bases scientifiques des conférences sanitaires: 1851-1938. Genebra OMS, 1975. (Col Histoire de la santé publique), e in crônicas OMS, abr./nov. 1974 e La santé publique internationale entre les deux guerres, Chron. OMS, 1977, p. 423-436 e 485-497, 1978, 68-80, 125-136 e v. 168-180. A título complementar v. BÉLANGER, M. L'Organisation d'hygiene de la Société des Nations. In: LECA, A.; VIALLA, F. Le risque épidémique, droit, histoire, médecine, et pharmacie. Colóquio em Aix-emProvence, nov. 2002. Aix: Prensa Universitária de Aix-Marseille, PUAM, 2003. p. 201 e S., Les actions de protection sanitaire en mer ou au port, in droit maritime français, out. 1981, p. 579-589; LACAISSE, R. La société de nations et la politique sanitaire internationale. Tese universitária da Faculdade de Direito de Paris, 1925; SDN. La protéction de la santé publique. Genebra: Seção de informação, 1939. (Col. Les activités de la Société des Nations, n. 12); BANKESTEIN, H. Van. L'organization d'hygiene de la Société des Nations. 2d. J. Muusses-Purmerend, 1934.

(10) Como por exemplo o Conselho da Europa e a Comunidade Européia. Nesse aspecto ver nosso estudo in Lamy Direito à saúde, estudo n. 137, "Institutions européennes", out. 2002. 
organização especializada com objetivos sanitários, num plano universal, tem permitido o crescimento do DIS. Muitas disciplinas jurídicas internacionais trazem sua colaboração para a elaboração de uma verdadeira proteção internacional à saúde como um direito da pessoa humana: o Direito Internacional do Trabalho, o Ambiental, o Direito internacinal médico e o humanitário etc. Retomaremos a análise de Bélanger, segundo a qual a especificidade do DIS está no fato que ele deve ser considerado como um direito de proteção internacional da saúde humana em tempos de paz ${ }^{(11)}$.

Um direito que é analisado como um direito à proteção internacional à saúde humana. Historicamente, o DIS foi dominado por regras apoiadas numa concepção defensiva ou negativa da saúde. As nações conscientizaram-se muito cedo da necessidade de se protegerem contra as calamidades públicas, como eram consideradas as grandes epidemias. Tratavase principalmente de organizar a defesa da Europa contra as doenças de quarentenas (conselhos de quarentenas, conferências sanitárias internacionais, convenções internacionais), as quais começaram com a peste, a cólera e a febre amarela e, depois, seguiram com a variola, em 1926, e o tifo. Essa tendência defensiva existe, ainda hoje, e o atual Regulamento Sanitário Internacional (RSI) parece como que representar, por excelência, essa concepção negativa. Entretanto, sob o impulso da OMS, além do conceito das moléstias de quarentenas, o conceito de doença sob vigilância ocupa um lugar cada vez mais importante, o que pode ser interpretado como uma maleabilidade. A dimensão negativa do DIS e das normas que o compõem têm tido, desde 1980, um novo interesse sobre a matéria, principalmente na luta contra o flagelo da SIDA.

Entretanto, progressivamente, iremos assistir a um aumento da força de uma abordagem ofensiva ou positiva da proteção sanitária internacional, que, de fato, tornou-se dominante no DIS. Hoje, a norma sanitária internacional é principalmente uma norma apoiada na abordagem positiva. Essa concepção integra todos os fatores e todas as dimensões que concorrem à proteção efetiva da saúde. Foi assim que logo estabeleceram-se estatísticas sanitárias internacionais (desde 1855), depois a classificação internacional das doenças traumáticas causadoras de óbitos e a classificação dos impedimentos (1980, no quadro da OMS). Registrou-se um grande número de ações, de lutas contra as doenças não transmissiveis e transmissiveis, com uma abertura preventiva importante, que ao mesmo tempo integra a prática dos tratamentos primários de saúde, ou as ações de lutas contra os grandes males sociais, tais como a droga, o alcoolismo ou o fumo, que são fundamentais nesta abordagem (como, por exemplo, a luta contra o câncer) ${ }^{(12)}$.

(11) Cf. BÉLANGER, M. Droit international de la santé par les textes. Paris: Ed. Berger-Levrault. 1989. p. 34.

(12) V. BÉLANGER, M. Le droit international de la santé, cit., p. 65 et s. 
Um Direito como Direito em tempos de paz: o Direito internacional humanitário e o Direito internacional médico (proteção dos profissionais de saúde em tempo de guerra) são as áreas mais antigas do DIS e seu desenvolvimento está ligado ao contexto histórico do século $X X$, abalado pelos dois grandes flagelos que foram as guerras mundiais. Os princípios e regras desses Direitos são os únicos utilizáveis na prática.

Depois da Segunda Grande Guerra Mundial, a comunidade internacional, com a instalação do sistema das Nações Unidas, acolheu a idéia de que era preciso desenvolver um DIS, posição constatada nos anos $70 \mathrm{com} o$ crescimento de potências do terceiro mundo e da conscientização sobre os grandes problemas e as questões sanitárias desses países. Foi dessa forma que o DIS conseguiu e teve que se destacar. Além disso, na realidade, em casos de conflitos armados, o DIS é praticamente inaplicável. Num plano global, o DIS como instrumento das políticas e estratégias internacionais em matéria de saúde, aparece como um aspecto importante e de estrutura do direito à paz, uma vez que é um fator de ligação da comunidade internacional, além de fixar o quadro de cooperação sanitária internacional. Entretanto, a doutrina evidencia os limites de especificidade do DIS, como direito do tempo de paz. A saúde é um dos direitos fundamentais do ser humano. Portanto, é totalmente falso fazer uma distinção na área de proteção internacional da saúde entre as regras aplicáveis em tempos de paz e de conflitos armados. A própria atividade da OMS é prova de sua preocupação quanto às questões de saúde em tempo de conflitos armados (cf. solicitação de parecer à Corte Internacional de Justiça $(\mathrm{ClJ})$ quanto aos efeitos das armas nucleares).

\section{B - As particularidades do DIS}

O DIS caracteriza-se pela grande variedade de seus recursos. Os tratados internacionais são poucos, o costume é quase inexistente, a jurisprudência internacional aparece pouco desenvolvida ${ }^{(13)}$, as fontes são essencialmente formadas pelos mapas constitutivos das organizações internacionais, bem como pelos atos de objetivo sanitário ou por meio da aplicação de competências sanitárias (principalmente recomendações) das organizações. Note-se que, até o momento, a OMS só fez uma convenção, a saber a convenção-quadro da luta contra o fumo, adotada em 21 de maio de 2003, a qual, aliás, ainda não entrou em vigor ${ }^{(14)}$.

(13) Isso é diferente no quadro dos direitos regionais e principalmente no âmbito do direito comunitário. A Comissão Interministerial para a Comunidade Europeia (CICE), desde os anos 70 , desenvolveu uma jurisprudência importante, que favorece o desenvolvimento de um direito comunitário da saúde.

(14) WHA56.1 de 21 de maio de 200 da Assembléia Mundial da Saúde (MAS): o texto da convenção está anexo à resolução da MAS. 
O DIS é caracterizado a seguir por uma heterogeneidade de normas. Além de normas sanitárias jurídicas (como por exemplo o Regulamento Internacional Sanitário da OMS e as normas elaboradas pelos organismos tais como o Codex Alimentarius etc.), há um grande número de normas sanitárias técnicas. A inflação dessas últimas é sem dúvida o elemento dominante do Direito Internacional da Saúde, o que em nada surpreende, uma vez que o desenvolvimento deste Direito está intimamente ligado à evolução das ciências e das tecnologias nas áreas médica e social.

Enfim, o DIS é um Direito que tem uma dimensão ideológica marcante, entrelaçado com pretensões ideológicas fortes a partir dos anos 60-70. Alguns conceitos do terceiro mundo de proteção à saúde foram admitidos e explicitados através de organizações internacionais, principalmente da OMS (conceito de nova ordem sanitária internacional, de tratamentos primários de saúde, de cooperação sanitária entre países em desenvolvimento etc.).

\section{II - UM ASPECTO ORIGINAL DA LEGISLAÇÃO DA OMS: O CASO DO REGULAMENTO SANITÁRIO INTERNACIONAL}

Antes de nos atermos ao aspecto mais singular da legislação da OMS, a saber, o Regulamento Sanitário Internacional, convém destacar mais precisamente o conceito em si de "legislação da OMS".

\section{A - O conceito de legislação da OMS}

A expressão "legislação da OMS" deve ser abordada aqui de forma muito ampla. Ela abrange o conjunto da produção normativa da OMS, instituição especializada que não possui constitucionalmente poderes legislativos. Numa perspectiva mais estrita, a LSI produzida por essa instituição remete à legislação convencional (lembrando que até o presente a única convenção internacional elaborada pela OMS é a convenção contra o fumo adotada em maio de 2003) e seu poder quase regulamentar (art. 21) ${ }^{(15)}$, sendo que essa última dimensão é notável na ordem jurídica internacional. Entretanto, o direito da OMS não pode ser reduzido apenas a esses aspectos. Numa ampla perspectiva, parece necessário integrar o conjunto dos textos, particularmente as recomendações e códigos de boa prática ${ }^{(16)}$.

O impacto das normas não constrangedoras no Direito internacional público (soft law), e mais particularmente as que aqui nos prendem, não é negligenciável, como, às vezes, se diz afoitamente. O Direito produzido pela

(15) Cf. Constituição da OMS, art. 21.

(16) Para uma apresentação sintética da produção normativa da OMS v. BEIGBEDER, Y.

L'Organisation mondiale de la santé. p. 45 et s. (Col. QSJ, n. 3234). 
OMS reúne uma variedade de expressões normativas que se cruzam entre si, conseguindo formar um conteúdo bastante coerente. A coexistência das regras imperativas e das normas mais maleáveis de natureza muito variável caracteriza a legislação da entidade. Evidentemente, isso permite explicar porque o efeito dessas normas depende da boa vontade dos países. As normas contidas nas diversas resoluções, recomendações e declarações da OMS têm um apelo proclamador ou programador, elas concorrem com o Direito "duro", que comporta obrigações precisas complementadas por sanções. Com certeza, podemos dizer que o lugar tomado pela soft law é um dos sintomas de uma crise do sistema normativo internacional. Nem por isso a soft law deixa de ter uma influência importante sobre a evolução do conteúdo das regras jurídicas internacionais e do seu modo de formação. Ademais, é preciso dizer, a legislação da OMS tem que se adaptar constantemente, em vista dos progressos científicos e técnicos; assim, podemos entender melhor o lugar ocupado pela soft law.

O essencial da atividade normativa da OMS é de natureza constrangedora(17). A recomendação constitui o modo privilegiado de ação da instituição e mostra-se como um instrumento que tem a vantagem da maleabilidade, uma vez que é modificável sem formalidade. Privilegiando a eficácia, a OMS opta pela persuasão, sendo que, o objetivo é um termo de integração no Direito nacional. As resoluções da OMS têm freqüentemente uma função de impulsão, trata-se de fixar um quadro para uma ação internacional de proteção à saúde em diversos domínios, visando favorecer a harmonização das legislações nacionais ${ }^{(18)}$.

Se as recomendações têm apenas o valor de um simples aviso, devese notar, e é preciso sublinhar, que algumas recomendações da OMS são executórias, quase obrigatórias. Daremos aqui dois exemplos. No caso das Denominações Comuns Internacionais (DCl), de maneira caricatural, podemos considerá-las como nomes de substâncias farmacêuticas. Pois bem, as $\mathrm{DCl}$ são elaboradas a partir de listas propostas aos países, para que esses possam formular objeções e, caso não haja nenhum comentário, as $\mathrm{DCl}$ são encaminhadas. A partir desse momento, os Estados devem adotálas como Denominações Comuns Nacionais, tomando as medidas legislativas e regulares adequadas. O outro exemplo diz respeito às normas alimentares adotadas pela Organização das Nações Unidas para a Agricultura e Alimentação (FAO), incluídas no Codex Alimentarius; quando aceitas, os governos têm a obrigação de introduzirem nessas normas especificações no Direito nacional, bem como de garantir que sejam respeitadas.

(17) Cf. nosso estudo, La prise em compte des normes OMS par le droit français, op. cit. p. 97. (18) Distinguiremos globalmente as resoluções que pedem aos Estados que adotem medidas sanitárias (luta contra as doenças transmissiveis, luta contra a poluição etc.) e as que prevêem normas, dos princípios diretores ou códigos de boa conduta, visando propor às nações integrá-las na sua legislação nacional. 


\section{B - O Regulamento Sanitário Internacional (RSI): o exemplo de uma ver- dadeira legislação sanitária}

Com o RSI estamos diante de uma verdadeira legislação sanitária internacional. Esse texto é completamente emblemático na medida em que retomou, fazendo a devida revisão, as disposições das treze convenções sanitárias internacionais elaboradas entre 1903 e 1944. Até o momento, é o único instrumento internacional em matéria de saúde para as doenças transmissiveis tendo força constrangedora para os Estados-Membros ${ }^{(19)}$. Se numa primeira abordagem o RSI conseguiu atender às necessidades da comunidade internacional, por ocasião de sua adoção, ele aparece há alguns anos como instrumento de luta contra as doenças transmissiveis já ultrapassadas, o que explica o processo de revisão que foi iniciado pela OMS no decorrer destes últimos anos.

\section{A especificidade do poder regulamentar da OMS}

Poucas organizações de ordem internacional são dotadas de poder regulamentar. Esse poder, estritamente enquadrado, é usado com cautela pelas instituições especializadas.

Segundo o art. 21 da Constituição da OMS: "A Assembléia Mundial da Saúde terá autoridade para adotar os regulamentos de: a) determinada medida sanitária e de quarentena, ou outro procedimento, com a finalidade de impedir o alastramento das doenças de um pais a outro; b) a nomenclatura das doenças, as causas de mortandade e as metodologias de higiene pública; c) os métodos de diagnóstico aplicáveis na ordem internacional; d) as normas relativas à inocuidade, à pureza da atividade dos produtos biológicos, farmacêuticos e similares que estão no comércio internacional; e) as condições relativas à publicidade e à designação de produtos biológicos e farmacêuticos, bem como similares que estão no comércio internacional".

As regras adotadas para execução do art. 21 entrarão em vigor para todos os Estados-membros e sua adoção pela AMS foi rigorosamente notificada, com exceção daqueles países que poderiam comunicar ao diretor geral, nos prazos devidos a contar da notificação, que eles se recusam a adotar as regras em questão ou têm objeções a respeito(20).

(19) OMS. Emerging and other communicable disease: stategic plan 1996-2000. Divisão das doenças emergentes e outras transmissiveis, vigilância e luta, 1996. Doc. WHO/EMC/96.1. Para uma apresentação da legislação internacional em matéria de luta contra as doenças transmissíveis, v. GOSTIN, L. O. Legislation sanitaire et maladies transmissibles: role du droit à une époque de menaces microbiennes. RILS, v. 49, n. 1, p. 213 e s., e principalmente no RSI, v. p. 221-223, 1998. (20) Cf. art. 22 da Constituição da OMS. 
Deve-se notar que, nos termos da Constituição da OMS, a AMS tem o poder de discutir e adotar diretamente um regulamento internacional sem que nenhum ato concreto de concordância do país seja necessário para manifestar, por parte dele, adesão ao regulamento (o regulamento OMS não pede ratificação). Esse texto é obrigatório para o Estado, salvo recusa explícita. A OMS, até o presente momento, faz uso com muita cautela do Regulamento Internacional. Apenas dois regulamentos foram adotados pela OMS: o Regulamento n. 1 sobre a Nomenclatura das Doenças e Causas de Morte, inclusive o estabelecimento de estatísticas e o Regulamento Sanitário Internacional n. 2, adotado em 1969.

\section{As especificidades do RSI}

Antes da Segunda Grande Guerra Mundial, a legislação sanitária revelou-se sem grande efeito, pois os textos não conseguiam seguir o ritmo do progresso científico; ela não era reconhecida por todos os países e não era aplicada pelos países mais pobres, pois eles não notificavam os casos de doença temendo eventuais conseqüências (econômicas, turísticas etc.). Há várias razões pelas quais a OMS, ao substituir, em 1951, a Organização Internacional de Higiene Pública, iniciou a publicação do Regulamento Sanitário Internacional. Um novo regulamento foi adotado em 1969, completado por um adendo regulamentar em 1973, que foi modificado em $1981^{(21)}$.

Fonte principal do Direito internacional referente às doenças transmissíveis, o RSI é o único instrumento com força constrangedora para os países e tem como finalidade máxima a garantia de segurança para a não propagação de moléstias de um país ao outro, com o mínimo de impedimentos no intercâmbio mundial. O regulamento é aplicado às diversas formas de transporte internacional e impõe uma série de obrigações às nações, particularmente a de notificar à OMS o aparecimento de doenças de quarentena, como peste, cólera e febre amarela, além de prever ações para serem adotadas no combate a sua propagação (normas sanitárias nos aeroportos, nos portos, medidas formais com referência às pessoas e às mercadorias, como as quarentenas etc.). Acrescente-se que regulamento em si é acompanhado de anexos e apêndices, como o anexo III que fixa as obrigações das administrações sanitárias nacionais e 0 anexo $\mathrm{V}$ que determina as normas de higiene a bordo de aeronaves que transportam pessoas participantes de reuniões periódicas importantes. Por fim, o RSI coloca o principio da vacinação preventiva para as doenças de quarentena como obrigatório (febre amarela). $\mathrm{O}$ art. 23 do $\mathrm{RSI}$ dispõe que as medidas sanitárias "constituem o máximo que um Estado pode exigir quanto ao tráfego internacional para a proteção de seu território contra as doenças submetidas ao regulamento".

(21) REGULAMENTO Sanitário Internacional (1969). 3. ed. corr. Genebra: OMS, 1983. 
No entanto, o regulamento vai além, uma vez que detalha as medidas sanitárias que normalmente integram as competências de cada nação. $O$ RSI atenua a soberania do Estado e concede um direito de investigação nas "zonas infectadas", notadamente para a OMS. A noção de zona infectada não deve ser analisada em termos de Estado ou parte dele, mas sim como uma zona definida com base nos princípios epidemiológicos pela administração sanitária, que assinala a existência da doença em seu país, não correspondendo necessariamente aos limites administrativos (art. $1^{\circ}$ do RSI).

Acabamos de ver que a adoção do RSI tratou da garantia de uma proteção máxima contra a propagação das doenças, bem como de evitar ao máximo perturbar a circulação internacional das pessoas e dos bens. Porém, mesmo a OMS não tendo poder algum para fazer aplicar os textos, havia a esperança de que uma ação de persuasão, bem como as recomendações da entidade, estimularia os países a respeitá-los. Contudo, a realidade foi outra: muitas nações não assinalavam casos de doença, justificando sua atitude por receio das conseqüências custosas observadas junto aos países que declaravam surtos de uma doença(22). Em vista da pouca eficácia do RSI, decidiu-se que seria feita uma revisão desse texto.

\section{Em direção da necessária revisão do RSI}

Segundo o relatório de 1996 sobre a saúde no mundo, publicado pela OMS, no decorrer dos vinte últimos anos mais de trinta novas doenças apareceram, das quais uma grande parte é de fácil propagação, com grande rapidez ${ }^{(23)}$. Ora, o RSI não prevê mecanismos que permitam notificar essas novas ameaças. Desde 1995, iniciou-se um processo de revisão, de modo a controlar mais as novas doenças e as que reaparecessem. Por ocasião da última AMS, em maio 2003, foi anunciado que o regulamento revisado deveria ser adotado pela 58 ${ }^{\text {a }}$ AMS, em 2005 (WHA56.28 revisão do Regulamento Sanitário Internacional). Há uma necessidade urgente de começar a elaborar um novo regulamento: o exemplo da emergência e da propagação internacional e rápida da síndrome respiratória aguda grave (SARS) é uma demonstração concreta do tamanho dos problemas e da inadequação do regulamento atual. Um dos objetivos é o máximo de segurança contra a transmissão de doenças, por meio do menor número de impedimentos. Ora, o atual RSI, na qualidade de ferramenta regulamentar mundial para a vigilância das doenças, tem muitas falhas e limitações:

- uma cobertura limitada: apenas a cólera e a peste febre amarela são visadas;

(22) Cf. CASH, R.A.; NARASIMHAN, V. Obstacles à la surveillance mondiale des maladies infectueuses: conséquences de la notification publique dans une économie mondialisée. Bulltein de I'OMS, n. 4, p. 189, 2002.

(23) RAPPORT sur la santé dans le monde 1996. Combattre la maladie, promouvoir le développement. Genebra: OMS, 1996. 
- o sistema depende das notificações dos Estados: o RSI depende totalmente da notificação oficial à OMS por parte do país que teve um surto de alguma das doenças em questão;

- o RSI tem falta de instrumentos para pressionar os países a aderir a tais solicitações;

- faltam ações especificamente relativas às diferentes situações: atualmente a OMS não dispõe da capacidade de decidir medidas específicas para prevenir a propagação internacional de uma doença. As medidas do RSI não podem ser adaptadas a casos específicos.

Em outras palavras, o princípio de segurança máxima só diz respeito a essas três doenças; além do que, não há no RSI especificações de procedimentos necessários para lutar contra novas doenças ou reincidentes, e a obrigação de notificação não resulta em processo que permita notificar um determinado número de doenças que representem um risco internacional. Os exemplos de surto de cólera no Peru e de peste na Índia mostraram que as regras internacionais não conseguiram prevenir as perdas econômicas e a perturbação social|(24).

O processo de revisão, que tem como objetivo o reforço do papel do RSI na luta mundial contra as doenças, leva em consideração a reticência dos países em notificar os casos - com receio de reações desmedidas impostas nos intercâmbios comerciais e nas viagens -, a falta de meios de detecção adequada e a aplicação limitada do regulamento atual. A revisão articula-se em duas vertentes. Primeira, um documento-quadro define as medidas de saúde pública a serem tomadas por ocasião de um surto, bem como as disposições legais que dizem respeito ao funcionamento do RSI e, logo a seguir, uma segunda vertente, que traz uma série de anexos indicando as disposições técnicas e as condições específicas.

O traço característico do projeto de revisão(25) é o alargamento do campo das doenças a serem notificadas, de forma a incluir toda patologia que apresente de imediato alguma importância para a saúde pública internacional. Serão incluídas "as doenças associadas a um forte potencial de propagação externa, a uma taxa de mortalidade muito alta, a um fato não habitual ou inesperado, a uma sindrome nova, a um fenômeno apresentando importância no plano político ou de comunicação, ou ainda a um risco de restrição dos intercâmbios comerciais ou de viagens"(26). Para resumir, são síndromes que implicam uma urgência em saúde pública internacional,

(24) CASH, R.A.; NARASIMHAN, V. op. cit., p. 192.

(25) Cf. na revisão do RSI, THE REVISION of IHR. Genebra: OMC, 1998. (doc. não publicado G?SPSGEN59; REVISÃO do Regulamento Sanitário Internacional: relatório da situação, jul. 1999. Rel. Epidemiológico Sem., v. 74, n. 30, p. 252-253, 1999.

(26) CASH, R.A.; NARASIMHAN, V. op. cit. 
que deverão de imediato ser notificadas e que deverão, a seguir, ter um relatório sobre a doença implicada, tão logo se tenha a informação etiológica pertinente.

A principal orientação desta revisão é a de que é mais eficaz combater as doenças infecciosas, em nivel mundial, seguindo estratégias de vigilância e de intervenção - as quais serão beneficiadas com o progresso técnico e científico nas áreas de comunicação, diagnóstico, e tratamento de infecções - do que adotar medidas de quarentena, ou quaisquer outras, em locais afastados da fonte de infecção.

\section{A integração do RSI no direito francês}

A França não fez reserva com relação ao RSI. Ele é o fundamento do Direito positivo francês em matéria de controle sanitário desde a Lei n. 65510 , de $1^{\circ}$ de julho de 1965, nas fronteiras terrestres, marítimas e aéreas. Nos termos do art. L. 3115-1 do Código de Saúde Pública francês, o controle sanitário nas fronteiras é regido pelas disposições dos regulamentos sanitários definidos pela OMS, pelos acordos internacionais e pelas leis e regulamentos nacionais. A primeira publicação do RSI n. 2 revisto de 1969 remonta ao Decreto n. 71-547, de 15 de junho de 1971 (JO 9 juillet). Desde então, o RSI foi revisto em 1971, depois em 1981; foi necessário esperar o ano de 1989 para que o regulamento já revisado fosse integrado de fato ao Direito francês, pelo Decreto n. 89-38, de 24 de janeiro de 1989, que trouxe a publicação do regulamento. (Note-se que textos nacionais organizando o controle sanitário nas fronteiras se apóiam e esclarecem certas prescrições do RSI).

O que dizer, então, do problema da aplicabilidade direta e imediata das normas provenientes do RSI em Direito interno? É forçoso constatar que é muito difícil encontrar um contencioso relativo a um texto da OMS. O único exemplo que pudemos encontrar foi a decisão da Corte de Apelação de Paris, de 18 de novembro de 1967 (époux Pivert), a qual afirma que o RSI não pode se aplicar se não for introjetado em um texto francês"(27). Este caso referente a duas pessoas retornando da Tunísia para a França, mas que não dispunham de um certificado válido de vacinação contra a varíola quando da sua chegada no país Europeu e que se recusavam a submeter-se à vacinação, apesar da intervenção dos serviços sanitários do aeroporto. Essa jurisprudência é bastante criticável na medida em que o RSI é aplicável de pleno direito no Direito interno. É preciso, com efeito, lembrar que o art. 22 da constituição da OMS afirma muito claramente que nenhuma intervenção prévia é necessária para a entrada em vigor do RSI. De fato, a decisão regulamentar é nela mesma um ato perfeito do ponto de vista internacional.

(27) KHAN, PH, Journal de Droit International, p. 728-729, 1968. 


\section{C - Perspectivas e futuro do RSI - as questões relacionadas às notifi- cações de doenças e suas conseqüências econômicas e sociais ${ }^{(28)}$}

As regras do RSI entram, às vezes, em conflito com regras contidas em outros acordos internacionais, notadamente no domínio comercial. Diante dos receios de que restrições desmedidas sejam impostas aos intercâmbios internacionais e às viagens, o RSI e o acordo da OMC que trata da aplicação de medidas sanitárias e fitossanitárias indicam as ações a serem adotadas. Na sua atual forma, o regulamento enumera as medidas que os Estados podem tomar, delimitando as linhas mestras específicas para os surtos de peste, cólera e febre amarela. Entretanto, apesar dele estabelecer as regras relativas à chegada e saída de navios e aeronaves e aquelas relativas ao tratamento das mercadorias importadas, essas regras não são bem detalhadas para fazer face às situações atípicas. Foi por essa razão que se propôs incluir, no futuro RSI revisado, anexos nos quais serão fixados limites às medidas a serem tomadas. Outra proposição é a de criar comissões de arbitragem para a regulação das diferentes tarifas relativas às práticas comerciais, após a ocorrência de um surto. Quanto à OMC, ela se serve do acordo em questão para elaborar regras de base, indicando quando os Estados podem aplicar o que seria normalmente considerado como prática comercial desleal, para limitar a entrada de mercadorias, que não atendam aos critérios de segurança. Se as medidas do acordo indicam que os países têm o direito de se proteger, eles não devem, entretanto, adotar medidas extremas, a menos que fatos científicos as justifiquem ${ }^{(29)}$. Conforme lembrado por vários autores, há fortes probabilidades de que os Estados definam ações protetoras por causa do relaxamento das restrições comerciais do acordo geral quanto às tarifas aduaneiras e o comércio(30). Para evitar que isso ocorra, as nações estão autorizadas, em razão das medidas sanitárias e fitossanitárias, a submeterem sua política que tenha sido contestada a um grupo de peritos para exame e consulta. Com o intuito de facilitar as consultas ou as negociações ad hoc entre os membros, é igualmente previsto a instituição de um comitê( ${ }^{(31)}$. Podemos constatar que, em vista da harmonização das linhas mestras nacionais, a OMC reconheceu que certos grupos, tais como a comissão do Codex Alimentarius, ou o Escritório Internacional de Epizootias, elaboram normas internacionais nas quais são fundamentadas medidas apropriadas a serem tomadas.

(28) Este trecho baseia-se nas análises e informações mencionadas no artigo de CASH, R. A.; NARASIMHAN, V. op. cit.

(29) Information paper1: a comparision os the functions and requirements in public health trade, OMS 1999 (doc. WHO/CDS/CSR/99.2) mencionado por CASH, R.A.; NARASIMHAN, V. op. cit., p. 191.

(30) CASH, R.A.; NARASIMHAN, V. op. cit., p. 191.

(31) Cf. UNDERSTANDING the WTO agreement on sanitary and phytosanitary measures. Genebra: OMC, 1998. 
Entretanto, a Organização Mundial da Saúde e a Organização Mundial do Comércio (OMC) compreendem que precisam colaborar entre si, para evitar conflitos entre as regras do RSI e aquelas do acordo para a aplicação das medidas sanitárias e fitossanitárias. Conforme lembram $R$. A. Cash e $B$. Narasimhan, "porque não existe acordo exato entre as duas organizações", aventou-se a idéia de que a OMS e a OMC contribuiriam para garantir que os Estados adotem as medidas de saúde pública exigidas para o combate de um surto de doença.

Em face de uma epidemia, a comunidade internacional reage freqüentemente de forma desproporcional e o Estado atingido, que a notifica, arriscase a ter maiores perdas econômicas. Se a maioria dos países adota uma postura pertinente, respeitando as linhas mestras da OMS e da OMC, há também aqueles que não as respeitam, além de adotarem medidas excessivas, sem informações científicas, sobre o risco de doença ou de ações preventivas. Em outras palavras, isso significa que essas linhas mestras não permitem proteger o país que notifica uma patologia; portanto, seria oportuno que as organizações internacionais revisassem sua regulamentação, reforçando as orientações principais e exigindo o respeito a elas. Ora, os poderes da OMS são fracos para a aplicação do RSI, principalmente no que diz respeito aos capítulos relativos às reações internacionais às epidemias. Conseqüentemente, uma estratégia jurídica apoiada principalmente no RSI para controlar as doenças emergentes é sem dúvida discutível para nós.

Retomando, por conta própria, a análise de R. A. Cash e V. Narasimhan ${ }^{(32)}$, a estratégia jurídica deve integrar duas versões paradoxais: de um lado, "a globalização compromete a luta contra as doenças em nivel nacional" e, por outro, diante da necessidade de soluções internacionais, "o princípio de soberania pode atrapalhar a luta contra as doenças em nível mundial". Portanto, é preciso que os dispositivos jurídicos a ser definidos abordem verdadeiramente as questões de ingerência nos intercâmbios comerciais e turísticos.

No quadro do processo de revisão do RSI, propôs-se que a OMS pudesse impedir os países de aplicar medidas sanitárias extremas, sem a aprovação de um grupo de peritos. Todavia, devemos salientar aqui a existência de várias incógnitas: os Estados-membros iriam aceitar a concessão desse poder à OMS? Eles aceitariam a autoridade da organização? Um país em desenvolvimento, caso seja injustamente tratado por outras nações, deve saber que dispõe de meios para recorrer. Assim, será necessário que comitês de arbitragem propostos pelo RSI tenham autorização para regular as diferenças entre os Estados. Quanto à OMC, ela poderá apoiar-se no acordo SSP, para esse processo. Desta forma, um país poderá obter reparação dos danos causados pelas práticas comerciais desleais durante uma epidemia. É preciso, portanto, que a OMS e a OMC desenvolvam uma colaboração para que um Estado que declare um surto não seja penalizado injustamente.

(32) CASH, R.A.; NARASIMHAN, V. op. cit., p. 196. 
Para concluir, nessa dimensão tão particular da legislação da OMS que constitui o RSI, parece que o sistema de vigilância contra doenças transmissiveis, em cujo quadro o RSI será revisado, só poderá ser eficaz se a OMS, em parceria com a OMC, pensar e desenvolver novos meios de proteger os interesses dos Estados que notifiquem epidemias. De fato, por falta de ações desse tipo, é bem provável que as nações, em particular as mais pobres, continuem a ocultar as epidemias. É principalmente necessário o desenvolvimento, em nível internacional, de uma política de acompanhamento de ajudas econômicas, com a finalidade de incitar os países a declararem os surtos de doenças, pois disso depende a segurança sanitária do mundo.

\section{REFERENNCIAS}

ABBING, V. H. Roscam. "La santé, droits de l'home et droit de la santé; vers une internationalisation, en particulier dans le contexte européen". RILS, v. 49, n. 1, 1998.

ASH, R.A.; NARASIMHAN, V. "Obstacles à la surveillance mondiale des maladies infectueuses: conséquences de la notification publique dans une économie mondialisée". Bulltein de I'OMS, n. 4, 2002.

BANKESTEIN, H. Van. L'organization d'hygiene de la Société des Nations. 2d J. Muusses-Purmerend, 1934.

BEIGBEDER, Y. L'Organisation mondiale de la santé. (Col QSJ, n. 3234).

BÉLANGER, M. "Droit international de la santé". Revista de Québec de Direito internacional, v. 2, p. 11-18, 1985.

Levrault, 1989.

Droit international de la santé par les textes. Paris: Ed. Berger. Le droit international de la santé. Paris: PUF, 1997. (Col. QSJ n. 3234).

. "Organisation d'hygiene de la Société des Nations". In: LECA, A.; VIALLA, $\mathrm{F}$. Le risque épidémique, droit, histoire, médicine, et pharmacie. Colóquio en Aix-en-Provence, nov. 2002. Aix: Prensa Universitária de AixMarseille, PUAM, 2003. les actions de protection sanitaire en mer ou au port, in droit maritime français, out. 1981.

FLUSS, Serv. S. "The development of national legislation in Europe: " the contribuition of international organizations european", Journal of Health Law, n. 2, 1995.

GOSTIN, L. O. "Legislation sanitaire et maladies trnasmissibles: rôle du droit à une époque de menaces microbiennes", RILS, V. 49, n. 1, 1998.

HOWARD-JONES, N. "Les bases scientifiques des conférences sanitaires: 1851-1938", Genebra OMS, Col "Histoire de la santé publique", n. 1, 1975, e in Crônicas OMS, abr.-nov. 1974 e La santé publique internationale entre les deux guerres, Chron. OMS, 1977. 
KHAN, PH, Journal de Droit International, 1968.

LACAISSE, R. La société de nations et la politique sanitaire internationale. Tese Universitária da Faculdade de Direito de Paris, 1925.

MONDIELLI, E. "La prise em compte des normes OMS par le droit français", RGDM, n. 1, p. 87-116.

OMS. "Emerging and other communicable disease: strategic plan 1996-2000". Divisão das doenças emergentes e outras transmissiveis, vigilância e luta, 1996. Doc. WHO/EMC/96.1.

RAPPORT sur la santé dans le monde 1996. Combattre la maladie, promouvoir le développement. Genebra: OMS, 1996.

REGULAMENTO Sanitário Internacional (1969). 3. ed. corr. Genebra: OMS, 1983.

REVISÂO do Regulamento Sanitário Internacional: relatório da situação, jul. 1999. Rel. epidemiológico Sem., V. 74, n. 30, p. 252-253, 1999.

THE REVISION of IHR. Genebra: OMC, 1998. (doc. não publicado G?SPSGEN59

SDN. La protéction de la santé publique. Genebra: Seção de informação, 1939. (Col. Les activités de la Société des Nations, n. 12).

UNDERSTANDING the WTO agreement on sanitary and phytosanitary measures. Genebra: OMC, 1998.

VITTA, Cino. Le droit sanitaire international. RCADI, v. 33, p. 545-669, 1930.

VERSÃO EM FRANCÊS

\section{Brefs Considerations sur les Specificites des Normes Sanitaires Internationales en General et du Reglement Sanitaire International en Particulier}

\section{E. Mondielli(*)}

Que de chemin parcouru par le droit international de la santé, depuis les années 1930 où la doctrine considérait que "le droit sanitaire international' était une branche du droit administratif international(t). Ainsi que le relève

(*) Directeur adjoint du CERDES - Centre d'études et de recherches en droit européen de la santé, de Nantes.

(1) VITTA, Cino. Le droit sanitaire international RCADI vol. 33, 1930, pp. 545-669, v. p. 549. 
Michel Bélanger, cette branche du droit international public est fondamentalement un droit mixte, en ce sens qu'il mélange le droit administratif, le droit économique et le droit social(2). Le droit international de la santé apparaît comme une partie du droit international économique et une partie du droit international du développement. Le droit international de la santé et le droit communautaire de la santé, disciplines peu enseignées au sein des facultés de droit, sont des branches du droit relativement récentes et relativement méconnues par les internationalistes alors que les préoccupations sanitaires au plan international et régional prennent une place de plus en plus considérable (la question par exemple de l'accès aux médicament et aux soins, en particulier dans le cadre de la lutte contre le SIDA, est tout à fait exemplaire de ce point de vue). Dans le cadre de réflexion sur "les normes sanitaires internationales"(3), il semble essentiel de se pencher sur la question des spécificités et des caractères des normes sanitaires internationales ou régionales). L'objet modeste de cette contribution vise d'une part, à rappeler ce qu'est le droit international de la santé, et partant ce qu'il n'est pas, en tentant de mettre en évidence ces traits saillants, et, d'autre part, à mettre en perspective, en s'appuyant sur des exemples concrets, la manière dont ce droit exerce une influence sur le droit français.

A titre liminaire, il semble nécessaire de donner une définition sommaire de ce qu'est le droit international de la santé (DIS). Cette branche du droit international public a pour objet d'étudier les règles juridiques applicables par la communauté internationale aux actions de santé, ces règles étant produites essentiellement par les organisations internationales et régionales. Le principal intérêt de cette définition est de mettre en évidence que la production normative internationale dans le secteur de la santé est essentiellement le fruit de l'action diverses d'organisations internationales. Toutefois, du fait de la très grande diversité des sources des normes sanitaires internationales, ainsi que de leur grande hétérogénéité(4), et pour limiter notre propos, la réflexion ne portera que sur la législation de l'Organisation mondiale de la santé (OMS). Ce choix est loin d'être arbitraire l'OMS étant au plan international la principale autorité directrice et coordonnatrice dans le domaine de la santé et des travaux ayant un caractère international(5), et la seule organisation à objet sanitaire.

(2) BÉLANGER, M. Le droit international de la santé, PUF, coll. QSJ n. 3234, 1997, p. 8.

(3) Cet article est une synthèse de notre communication faite dans le cadre du séminaire organisé par le CRUARAP consacré au thème. Les normes sanitaires internationales décembre 2003 (séminaire de recherche organisé par le professeur A. Fenet (Faculté de droit de Nantes), avec la participation du professeur M. Bélanger (faculté de droit de Bordeaux-Montesquieu.

(4) Sur ces aspects M. Bélanger, Droit international de la santé, Economica, 1983, Le droit international de la santé, PUF, coll. QSJ n. 3234, Réflexions sur la réalité du droit international de la santé, in Revue québécoise de droit international, 1985, vol. II, pp. 11-18;E. Mondielli, La prise en compte des normes OMS par le droit français, in RGDM, n. 1, pp. 87-116.; Sev. S. Fluss, The development of national legislation in Europe The contribution of international Organizations, European, in Journal of health law, 1995, n. 2, p. 193et s..

(5) Cf. Constitution de l'OMS art. 2, a). 
Le DIS se caractérise par une très forte institutionnalisation. Les organisations internationales contribuent largement à l'évolution du droit de la santé quant aux rapports entre santé et droit droits de l'homme tant au plan national qu'international(6). C'est presque une banalité de souligner que fréquemment le droit de la santé au plan national doit être complété par l'élaboration d'un corps de règles et de normes à l'échelon international ou régional. Ce travail est en fait assumé par un grand nombre d'institutions (intergouvernementales, et non gouvernementales). Depuis la fin du 2éme conflit mondial, la portée et l'incidence des activités internationales ont augmenté considérablement, tout comme le rôle joué par le droit de la santé. On doit souligner qu'à côté de l'OMS un grand nombre d'organisations internationales exercent des compétences d'ordre sanitaire (ONU, UNESCO, OIT, FAO etc.). Pour l'essentiel, l'élaboration du DIS résulte de leurs activités. Si les Etats participent à l'élaboration du DIS directement à travers la conclusion de conventions sanitaires, la plupart du temps à caractère bilatérales ou faiblement multilatérales, c'est dans le cadre des organisations intergouvernementales que leur participation à l'élaboration est la plus active et déterminante dans la mesure où ce sont eux qui en dernier lieu décident d'adopter ou non les textes proposés par les institutions internationales. La doctrine a eu l'occasion de montrer que le droit international de la santé est tiraillé par deux tendances institutionnelles antagonistes (en fait influencé par un double mouvement institutionnel), à savoir la recherche de la centralisation et la nécessité de la décentralisation. L'idée de centralisation sanitaire internationale ${ }^{(7)}$, il faut bien le dire, a en grande partie échouée. L'OMS, seule organisation à objet sanitaire (qui a succédé à l'Office international d'hygiène publique et à l'Organisation d'hygiène de la SDN), a vu, dès sa naissance, son activité concurrencée, voire limitée, par les compétences sanitaires exercées par les autres organisations du système des nations Unies.

L'augmentation des activités transfrontalières et du commerce international, et par voie de conséquence de la concurrence, a un impact sur de nombreuses dimensions des soins et des droits de l'homme connexes. L'intérêt commun des États et la nécessité impérieuse de fixer des règles et des lignes directrices internationales du fait des mouvements transfrontières permettent d'expliquer la place de plus en plus grande prise par le DIS. Cela permet d'expliquer le soutien donné par les organisations internationales au développement de la politique sanitaire de nombreux pays et l'élaboration de règles et de normes internationales et supranationales ayant force obligatoire. Le droit de la santé devenant de plus en plus tributaire de

(6) ROSCAM ABBING, V. H. La santé, droits de l'homme et droit de la santé: vers une internationalisation, en particulier dans le contexte européen, in RILS, 1998, vol. 49, n. 1, p. 99 et s.

(7) BÉLANGER, M. Le droit international de la santé, op. cit., v. notamment les considérations sur les limites de la centralisation sanitaire internationale, p. 19 et s. 
l'internationalisation et de la mondialisation du commerce, il faut donc que les organisations internationales, acteurs et auteurs, du DIS, fassent pleinement usages de leurs compétences afin d'empêcher que des considérations d'ordres économique ne prennent le pas sur les intérêts de la santé. La place prise par le DIS conduit en conséquence à s'interroger sur la spécificité des normes sanitaires internationales. Après avoir évoqué sur un plan général la question de la spécificité des normes sanitaires internationales, on accordera une attention particulière à l'un des aspects les plus originaux de la législation sanitaire internationale (LSI), à savoir le règlement sanitaire international.

\section{I- LA SPÉCIFICITÉ DES NORMES SANITAIRES INTERNATIONALES ${ }^{(8)}$}

Parler de la spécificité des normes sanitaires internationales, c'est en fait mettre en perspective la singularité ou les singularités de ces normes. Cette singularité tient à leurs caractères. Traditionnellement on distingue le droit de subordination et le droit de coopération. Le droit interne apparaît comme un droit de subordination (un seul ordre juridique, et des sujets subordonnés au pouvoir de l'État), tandis que le droit international public apparaît comme un droit de coopération élaboré entre États souverains directement (ou indirectement par ces derniers au sein des organisations internationales) dans l'ordre international. Le droit international public ne connaît ni législateur, ni juge, ni sanction obligatoire en dehors du consentement des États visés. Les normes sanitaires internationales n'appartiennent pas au droit de subordination dans la mesure où elles se développent dans le cadre de la société internationale. Toutefois, elles ne semblent pas participer exclusivement au droit de coordination puisqu'elles visent à affirmer un droit de la protection de la santé en tant que droit de l'homme au plan international. Les normes sanitaires internationales sont élaborées en fonction de l'intérêt de l'homme. II faut néanmoins souligner (l'histoire du droit international de la santé est là pour le rappeler ${ }^{(9)}$ ) que la plupart du temps se

(8) On préféra utiliser l'expression de normes sanitaires internationales plutôt que parler de la norme sanitaire internationale du fait de la grande variété et diversité de normes du droit international de la santé.

(9) Sur l'histoire du DIS et de la santé publique v. notamment N. Howard-Jones, Les bases scientifiques des conférences sanitaires internationales: 1851-1938, Genève OMS, Coll. Histoire de la santé publique, n. 1, 1975, et in Chroniques OMS, avril-novembre 1974 et La santé publique internationale entre les deux guerres, Chron. OMS, 1977, pp. 423-436 et 485-497, 1978, 68-80, 125-136 et v 168-180. A titre complémentaire v. M. Bélanger L'Organisation d'hygiène de la Société des Nations, in Le risque épidémique, Droit, histoire, médecine et pharmacie, Colloque d'Aix-en Provence, novembre 2002, sous la direction d'A. LECA et F. Vialla, Presses universitaires d'Aix-Marseille, PUAM, 2003, pp.201 et S., Les actions de protection sanitaire en mer ou au port, in Droit maritime français, oct. 1981, pp.579-589; R. Lacaisse La Société des Nations et la politique sanitaire internationale, Thèse Université de Paris Faculté de droit, 1925; SDN, La protection de la santé publique, Genève, section d'information, coll. Les activités de la Société des Nations n. 12, 1939; H. Van Blankenstein, L'organisation d'hygiène de la Société des Nations, 2d. J. Muusses- Purmerend 1934. 
sont davantage les préoccupations liées au souci croissant d'éliminer les obstacles au commerce et aux exportations et à la volonté de se protéger contre les "fléaux exotiques" que les préoccupations humanitaires qui sont à l'origine des actions publiques concertées en matière sanitaire (la volonté d'éradication des maladies transmissibles fut, faut-il le rappeler, la principale préoccupations des Etats européens, et les premiers textes de "législation sanitaire internationale" avaient un objectif limité, la lutte contre les maladies contagieuses).

Affirmer la spécificité du droit international de la santé et des normes qui le composent ne signifie pas qu'il ne puisse pas y avoir des interconnexions avec d'autres branches du droit international public, mais simplement qu'il se structure autour d'un noyau dur de principes et de règles qui le singularise. II s'agit donc d'identifier, de définir les caractéristiques de cette branche du droit international, tout en en intégrant l'idée que ces caractéristiques sont évolutives en fonction des mutations politiques et juridiques de la société internationale et des développements scientifiques et technologiques. De surcroît, les branches existantes ou émergentes, qui ont une dimension sanitaire, peuvent connaître elles-mêmes des évolutions qui les feront apparaître comme des branches du droit international à caractère hégémonique, ou du moins comme exerçant un pouvoir attractif sur d'autres secteurs disciplinaires.

\section{$A$ - Le DIS, une branche à part entière du droit international public}

Cette affirmation ne s'appuie pas sur de simples prétentions doctrinales. Le fait que diverses organisations internationales aient des compétences sanitaires au niveau international et régional(10), voire sous régional, et qu'il existe une organisation spécialisée à objet sanitaire au plan universel a permis l'essor du DIS. Plusieurs disciplines juridiques internationales apportent leur pierre à l'élaboration d'une véritable protection internationale de la santé en tant que droit de l'homme: le droit international du travail, le droit international de l'environnement, le droit international médical, le droit international humanitaire etc. On reprendra à notre compte l'analyse de M. Bélanger, selon laquelle la spécificité du DIS réside dans le fait qu'il doit être considéré comme un droit de la protection internationale de la santé humaine en temps de paix ${ }^{(11)}$.

Un droit qui s'analyse comme un droit de la protection internationale de la santé humaine:

Historiquement, le DIS a été dominé par des règles qui s'appuient sur une conception défensive de la santé ou négative. Les États ont pris cons-

(10) Comme par exemple le Conseil de l'Europe et la Communauté européenne. Sur ces aspects voir notre étude in Lamy Droit de la santé, étude n. 137, Institutions européennes, oct. 2002.

(11) Cf.M. Bélanger, Droit international de la santé par les textes, Berger-Levrault, sept. 1989, p. 34. 
cience très tôt de la nécessité de se protéger contre les fléaux qu'étaient les grandes épidémies et pandémies. Il s'agissait essentiellement d'organiser la défense de l'Europe contre les maladies dites quarantenaires (conseils quarantenaires, conférences sanitaires internationales, les conventions internationales). Ces maladies furent d'abord la peste, le choléra la fièvre jaune, par la suite ont y a ajouté la variole en 1926 et le typhus. Cette tendance défensive existe toujours aujourd'hui, l'actuel Règlement sanitaire international (RSI) apparaît comme incarnant par excellence cette conception négative. Cependant sous l'impulsion de l'OMS, à côté du concept de maladies quarantenaires, le concept de maladie sous surveillance prend une place de plus en plus importante ce qui peut être interprété comme un assouplissement. La dimension négative du DIS et des normes qui le compose connaît depuis les années 1980 un regain d'intérêt dans le cadre notamment de la lutte contre la pandémie du SIDA.

Toutefois, progressivement on va assister à une montée en puissance d'une approche offensive ou positive de la protection sanitaire internationale, qui est devenue en fait dominante dans le DIS. La norme sanitaire internationale aujourd'hui est essentiellement une norme qui s'appuie sur l'approche positive. Cette conception intègre tous les facteurs et toutes les dimensions qui concourent à protéger effectivement la santé. C'est ainsi que très tôt on s'est efforcé d'établir des statistiques sanitaires internationales (dès 1855), puis la classification internationale des maladies traumatismes et cause de décès, la classification des handicaps (1980 dans le cadre de l'OMS). Un grand nombre d'actions de lutte contre les grandes maladies non transmissibles ou transmissibles avec un volet prévention important tout en intégrant la pratique des soins de santé primaires, ou les actions de luttes contre les grands maux sociaux que sont la drogue, l'alcoolisme ou le tabac, se fonde sur une telle approche (l'exemple de la lutte contre le cancer) ${ }^{(12)}$.

Un droit en tant que droit du temps de paix: le droit international humanitaire et le droit international médical (protection des personnels de santé en temps de guerre) sont des branches plus anciennes que le DIS, le développement des ces deux branches du droit étant lié au contexte historique du 20ème siècle ébranlé par les deux grands séismes que furent les guerres mondiales. Les principes et règles de ces droits sont les seuls en pratique utilisables. Après le second conflit mondial, la communauté internationale, avec la mise en place du système des Nations Unies, a intégré l'idée qu'il fallait développer un DIS, et cette posture s'est accusée dans les années 70 avec la montée en puissance du Tiers-monde et la prise de conscience des immenses problèmes et enjeux sanitaires rencontrés par ces pays. C'est ainsi que le DIS a pu et dû se distinguer. De surcroît, en pratique, en cas conflits armés, le DIS est largement inapplicable. Sur un plan global, le DIS

(12) V. M. Bélanger Le droit international de la santé, PUF, op. cit, p. 65 et s. 
en tant qu'instrument des politiques et stratégies internationales en matière de santé, apparaît comme un aspect important et structurant du droit de la paix, puisqu'il est un facteur de cohésion de la communauté internationale, et qu'il fixe le cadre de la coopération sanitaire internationale. Toutefois, la doctrine met en évidence les limites de la spécificité du DIS en tant que droit du temps de paix. La santé est un des droits fondamentaux de l'homme, II est donc effet tout à fait artificiel d'opérer une distinction dans le domaine de la protection internationale de la santé entre les règles applicables en temps de paix et de conflits armés. L'activité même de l'OMS témoigne de sa préoccupation pour les questions de santé en période de conflits armés (cf. demande d'avis à la $\mathrm{ClJ}$ sur les effets des armes nucléaires).

\section{B - Les singularités du DIS}

Le DIS se caractérise par la grande variété de ces sources. Les traités internationaux sont peu nombreux, la coutume est quasi inexistante, la jurisprudence internationale apparaît très peu développée(13), les sources sont essentiellement constituées par les chartes constitutives des Organisations internationales et les actes des organisations à objet sanitaire ou ayant des compétences sanitaires (essentiellement des recommandations). On notera au passage que l'OMS n'a élaboré à ce jour qu'une seule convention, à savoir la convention-cadre de l'OMS pour la lutte antitabac, adopté le 21 mai 2003, qui d'ailleurs n'est pas encore entrée en vigueur ${ }^{(14)}$. Le DIS se caractérise ensuite par une forte hétérogénéité des normes. À côté de normes sanitaires juridiques (comme par exemple le règlement sanitaire international de l'OMS, les normes élaborées par des organismes tel que le Codex alimentarius etc.), il existe un grand nombre de normes sanitaires techniques. L'inflation des normes techniques est sans nul doute l'élément dominant du droit international de la santé, ce qui en soi n'a d'ailleurs rien de surprenant puisque le développement de ce droit est intimement lié à l'évolution des sciences et des technologies en matière socio-médicales.

Enfin, le DIS est un droit qui a une dimension idéologique marquée: il s'agit d'un droit traversé par des prétentions idéologiques fortes à partir des années 60-70. Certains concepts tiers-mondistes de protection de la santé ont été admis et explicités par diverses organisations internationales, et principalement l'OMS (concepts de nouvel ordre sanitaire international, de soins de santé primaires, de coopération sanitaire entre pays en développement etc.).

(13) Dans le cadre des droits régionaux, et principalement au plan du droit communautaire, il en va différemment. La CJCE depuis les années 1970 a développé une jurisprudence importante favorisant le développement d'un droit communautaire de la santé.

(14) WHA56. 1 du 21 mai 2003 de l'Assemblée mondiale de la santé (AMS): le texte de la convention est en annexe de la résolution de l'AMS. 


\section{II - UN ASPECT ORIGINAL DE LA LÉGISLATION OMS: LE CAS DU RĖGLEMENT SANITAIRE INTERNATIONAL}

Avant de nous intéresser à l'aspect sans nul doute le plus singulier de la législation OMS, à savoir le règlement sanitaire international, il convient de cerner plus précisément le concept même de "législation OMS".

\section{A - Le concept de législation OMS}

L'expression "législation OMS" doit être entendue ici de façon très large. Elle englobe l'ensemble de la production normative de l'OMS, l'institution spécialisée n'ayant pas constitutionnellement parlant des pouvoirs législatifs. Dans une perspective plus stricte, la LSI produite par cette institution renvoie à la législation conventionnelle (rappelons qu'à ce jour la seule convention internationale élaborée par l'OMS est la convention antitabac adoptée en mai 2003), et à son pouvoir quasi-réglementaire (art. 21) ${ }^{(15)}$, cette dernière dimension étant tout à fait remarquable dans l'ordre juridique international. Toutefois, le droit de l'OMS ne peut se réduire à ces aspects. Dans une perspective large, il semble nécessaire d'y intégrer l'ensemble des textes, en particulier les recommandations et codes de bonne conduite ${ }^{(16)}$. L'impact des normes non contraignantes en DIP ("soft Law"), et plus particulièrement celles qui nous retiennent ici, ne sont pas négligeables comme on a tendance un peu trop hâtivement de le dire parfois. Le droit produit par l'OMS réunit une variété d'expressions normatives qui s'interpénètrent les unes les autres, en parvenant à former un corpus assez cohérent. La coexistence de règles impératives et des normes plus souples de nature très variées caractérise la législation OMS. Bien évidemment, cela permet d'expliquer que l'effectivité des ces normes est amplement tributaire de la bonne volonté des États. Les normes contenues dans les diverses résolutions, recommandations et déclarations de l'OMS ont une portée proclamatoire ou programmatoire, elles concurrencent largement le droit "dur" lequel comporte des obligations précises assorties de sanctions. Certes, on pourra objecter que la place prise par la soft Law est un des symptômes d'une crise du système normatif international. II n'en demeure pas moins que la soft law a une influence importante sur l'évolution du contenu des règles juridiques internationales et de leur mode de formation. De plus, il faut relever que la législation OMS devant s'adapter de façon constante compte tenu des progrès scientifiques et techniques, on comprend mieux ainsi la place prise par la soft law.

(15) Cf. Constitution de l'OMS, art. 21.

(16) Pour une présentation synthétique de la production normative de l'OMS v. Y. Beigbeder, L'Organisation mondiale de la santé, Coll. QSJ, n.3234, p.45 et s. 
L'essentiel de l'activité normative de l'OMS est de nature non contraignante ${ }^{(17)}$. La recommandation constitue le mode privilégié d'action de l'institution spécialisée, cet instrument ayant l'avantage de la souplesse puisqu'il est modifiable sans formalité. L'OMS privilégiant l'efficacité opte pour la persuasion, l'objectif étant à terme l'intégration dans le droit national. Les résolutions OMS ont très fréquemment une fonction d'impulsion, il s'agit de fixer un cadre pour une action internationale de protection de la santé dans divers domaines en vue de favoriser l'harmonisation des législations nationales $^{(18)}$.

Si les recommandations n'ont la valeur que d'un simple avis, on doit noter, ce qui est remarquable à souligner, que certains recommandation OMS sont des recommandations exécutoires à portée quasi obligatoire. On en donnera deux exemples. Prenons le cas des Dénominations communes internationales $(D C l)$. Pour caricaturer les choses on considérera qu'elles sont des textes de substances pharmaceutiques. Les $\mathrm{DCl}$ sont élaborées à partir de listes proposées aux États afin que ces derniers formulent le cas échéant des objections ; en cas d'absence d'objections elles sont recommandées. Dés ce moment, les États doivent les adopter comme Dénominations communes nationales en prenant des mesures législatives et réglementaires adéquates. Le deuxième exemple concerne les normes alimentaires adoptées par la Commission FAO-OMS du Codex alimentarius, quand les normes codex sont acceptées, les gouvernements sont dans l'obligation d'en introduire les spécifications dans le droit national, mais aussi d'en assurer le respect.

\section{$B$ - Le règlement sanitaire international (RSI): l'exemple d'une véritable législation sanitaire}

Avec le RSI nous sommes en présence d'une véritable législation sanitaire internationale. Ce texte est tout à fait emblématique dans la mesure où il a repris, tout en les révisant, les dispositions des treize conventions sanitaires internationales élaborées entre 1903 et 1944. II est à ce jour le seul instrument international en matière de santé pour les maladies transmissibles ayant force contraignante pour les États Membres ${ }^{(19)}$. Si dans un

(17) Cf. notre étude, La prise en compte des normes OMS par le droit français, op. cit, p. 97.

(18) On distingue globalement les résolution demandant aux États d'adopter des mesures sanitaires (lutte contre les maladies transmissibles, lutte contre la pollution etc.) et celles prévoyant des normes, des principes directeurs ou code de bonne conduite en vue de proposer aux États de les intégrer dans leur législation nationale.

(19) OMS, Emerging and Other communicable Disease: strategic plan 1996-2000, division des maladies émergentes et autres maladies transmissibles-surveillance et lutte, 1996, doc. WHO/ EMC/96.1. Pour une présentation de la législation internationales en matière de lutte contre les maladies transmissibles v. L. O Gostin, Legislation sanitaire et maladies transmissibles: rôle du droit à une époque de menaces microbiennes, in RILS, 1998, 49 (1), p. 213 et s., et notamment sur le RSI, v. pp. 221-223. 
premier temps le RSI a pu répondre aux besoins de la communauté internationale lors de son adoption, il apparaît depuis quelques années comme un instrument de lutte contre les maladies transmissibles dépassé, ce qui explique qu'un processus de révision a été mis en œuvre par l'OMS au cours de ces dernières années.

\section{La spécificité du pouvoir réglementaire de l'OMS:}

Peu d'organisations dans l'ordre international sont dotées d'un pouvoir réglementaire. Ce pouvoir, très strictement encadré, est utilisé avec une grande prudence par l'institution spécialisée.

Aux termes de l'article 21 de la Constitution de l'OMS: "L'Assemblée de la Santé aura autorité pour adopter les règlements concernant: a) telle mesure sanitaire et de quarantaine ou toute autre procédure destinée à empêcher la propagation des maladies d'un pays à l'autre; b) la nomenclature concernant les maladies, les causes de décès et les méthodes d'hygiène publique; c) des standards sur les méthodes de diagnostic applicables dans le cadre international; d) des normes relatives à l'innocuité, la pureté et l'activité des produits biologiques, pharmaceutiques et similaires qui se trouvent dans le commerce international; e) des conditions relatives à la publicité et à la désignation des produits biologiques, pharmaceutiques et similaires qui se trouvent dans le commerce international".

Les règlements adoptés en exécution de l'article 21 entreront en vigueur pour tous les États Membres, leur adoption par l'AMS ayant été dûment notifiée, exception faite pour tels Membres qui pourraient faire connaître au Directeur général, dans les délais prescrits par la notification, qu'ils les refusent ou font des réserves à leur sujet ${ }^{(20)}$.

On voit qu'aux termes de la Constitution de l'OMS, l'AMS a le pouvoir de discuter et d'adopter directement un règlement international, et aucun acte concret d'acceptation de l'État n'est nécessaire de la part de l'État souhaitant adhérer au règlement (le règlement OMS ne demande pas de ratification). Ce texte est obligatoire pour l'État, sauf refus exprès. L'OMS jusqu'à ce jour utilise avec beaucoup de précaution le règlement international. Seuls deux règlement ont été adopté par l'OMS, le règlement $n .1$ sur la nomenclature des maladies et cause de décès, y compris l'établissement de statistiques, et le Règlement Sanitaire International n. 2 adopté en 1969.

\section{Les spécificités du RSI}

La législation sanitaire avant le $2^{\text {ème }}$ conflit mondial s'est avérée sans grand effet parce que les textes ne parvenaient pas à suivre le rythme du

(20) CF. art. 22 de la Constitution de l'OMS. 
progrès scientifique, elle n'était pas reconnue par tous les pays et elle n'était pas appliquée par les pays les plus pauvres, lesquels ne notifiaient pas les cas de maladie par crainte de répercussions éventuelles (économiques, touristiques etc.). C'est pour ces diverses raisons que l'OMS, lorsqu'elle a remplacé l'organisation internationale d'Hygiène publique, a publié dès 1951 le RSI. Un nouveau RSI fut adopté en 1969, complété par un règlement additionnel en date de 1973 et modifié en $1981^{(21)}$.

Source principale du droit international des maladies transmissibles, il est le seul instrument ayant force contraignante pour les États. II a pour but d'assurer le maximum de sécurité contre la propagation des maladies d'un pays à l'autre, moyennant le minimum d'entraves au trafic mondial, et s'applique aux diverses formes de transport international. II impose diverses obligations aux États membres, en particulier la notification à l'OMS des apparitions d'une maladie quarantenaire (peste, choléra, fièvre jaune) et une série de mesures devant être adoptées pour lutter contre sa propagation (normes sanitaires dans les aéroports, les ports, mesures de formalité touchant les personnes et les marchandises, comme les quarantaines etc.) de plus le règlement est lui-même accompagné d' annexes et d'appendices, ainsi l'annexe III fixe les obligations des administrations sanitaires nationales, l'annexe $V$ fixe les normes d'hygiènes à bord des aéronefs transportant des personnes prenant par à des rassemblements périodiques impor tants). Enfin, le RSI pose le principe de la vaccination obligatoire préalable pour les maladies quarantenaires (fièvre jaune). L'article 23 du RSI indique que les mesures sanitaires "constituent le maximum de ce qu'un Etat peut exiger à l'égard du trafic international pour la protection de son territoire contre les maladies soumises au règlement".

Le règlement va donc très loin puisqu'il détaille des mesures sanitaires qui, normalement relèvent de la compétence de chaque État. Le RSI atténue la souveraineté de l'État. II dote notamment l'OMS d'un droit d'investigation dans "les zones infectées". Cette notion de zone infectée ne doit pas s'analyser en termes d'État ou de partie d'État. Elle s'analyse comme une zone définie sur la base de principes épidémiologiques par l'administration sanitaire qui signale l'existence de la maladie dans son pays et ne correspondant pas nécessairement à des limites administrative (art. 1 du RSI).

Nous venons de voir qu'avec le RSI, il s'agissait d'assurer une protection maximale contre la propagation des maladies et d'éviter autant que possible de perturber la circulation internationale des personnes et des biens. Mais, l'OMS n'ayant aucun pouvoir pour faire appliquer les textes, on pouvait entretenir l'espoir qu'une action de persuasion et que les recommandations de l'institution spécialisée inciteraient les pays à le respecter. La réalité fut tout autre. On a vu par exemple des pays qui ne signalaient pas les cas de maladie, justifiant leur attitude par leurs craintes en évoquant les

(21) Règlement sanitaire international (1969) 3éme édition annotée, Genève, OMS 1983. 
répercussions coûteuses subies par les pays qui avaient notifié des flambées de maladie ${ }^{(22)}$. Vu le peu d'efficacité du RSI, il fut décidé de procéder à une révisiomn de ce texte.

\section{Vers la nécessaire révision du RSI}

Selon, le rapport sur la santé dans le monde de 1996 publié par l'OMS, au cours des vingt dernières années plus d'une trentaines de nouvelles maladies sont apparues, dont une grande partie est susceptible de se propager avec une grande rapidité à travers le monde ${ }^{(23)}$. Or le RSI ne prévoit pas de mécanismes permettant de notifier ces nouvelles menaces. Depuis 1995 un processus de révision est mis en oeuvre de façon à tenir compte davantage des maladies nouvelles et réémergences. Lors de la dernière AMS en mai 2003, il a été annoncé que le règlement révisé devrait être adopté par la 58éme AMS en 2005 (WHA 56.28 révision du règlement sanitaire international). II y a une véritable urgence à mettre en œuvre un nouveau règlement, l'exemple de l'émergence et de la propagation internationale rapide du syndrome respiratoire aigu sévère (SRAS) est une illustration concrète de l'ampleur des problèmes et de l'inadéquation du règlement actuel. L'un des objectifs est le maximum de sécurité contre la transmission des maladies moyennant le minimum d'entrave. Or, Le RSI actuel en tant qu'outil réglementaire mondial pour la surveillance des maladies comporte plusieurs faiblesses ou limites:

- une couverture limitée: ne sont visaient que le choléra, la peste la fièvre jaune;

- le système dépend des notifications des Etats: le RSI repose totalement sur la notification officielle à l'OMS de la part du pays connaissant une flambée de cas pour l'une des trois maladies en question;

- le RSI manque d'incitations pour pousser les Etats membres à adhérer à ses demandes;

- Il manque de mesures se rapportant spécifiquement aux différentes situations: actuellement l'OMS ne dispose pas de la capacité de fournir des mesures spécifiques pour prévenir la propagation internationale d'une maladie. Les mesures du RSI ne peuvent pas être adaptées à tel ou tel cas spécifique.

Autrement dit le principe de sécurité maximum ne concerne que ces trois maladies; de plus il n'y a pas dans le RSI de spécifications de procédu-

(22) Cf.R.A. Cash et V. Narasimhan, Obstacles à la surveillance mondiale des maladies infectieuses: conséquences de la notification publique dans une économie mondialisée, in Bulletin de l'OMS, n. 4, 2001, p.189.

(23) Rapport sur la santé dans le monde 1996, Combattre la maladie, promouvoir le développement, Genève, OMS 1996. 
res qui seraient nécessaires pour lutter contre les maladies nouvelles ou réemergentes et l'obligation de notification n'organise pas de procédure permettant de notifier un nombre important de maladies qui représentent un risque international. Les exemples de flambée de choléra au Pérou et de peste en Inde ont montré que les règles internationales n'ont pas réussi à prévenir des pertes économiques et une perturbation sociale ${ }^{(24)}$.

Le processus de révision, qui a pour objectif le renforcement du rôle du RSI dans la lutte mondiale contre les maladies, prend en considération la réticence des Etats à notifier des cas de crainte de réactions démesurées imposées aux échanges commerciaux et aux voyages, le manque de moyens de détection adéquate et, mais aussi la portée limitée du règlement actuel. La révision s'articule autour de deux volets. Tout d'abord, un documentcadre précise les mesures de santé publique à prendre lors d'une flambée ainsi que les dispositions légales concernant le fonctionnement du RSI, et ensuite d'une série d'annexes indiquent les dispositions techniques et les conditions spécifiques.

Le trait caractéristique de projet de révision ${ }^{(25)}$ est d'élargir le champ des maladies à notifier de façon à inclure toute pathologie présentant dans l'immédiat une importance pour la santé publique internationale. Seront incluses "les maladies associées à un fort potentiel de propagation extérieure, à un taux de létalité exceptionnellement élevé, à un fait inhabituel ou inattendu, à un syndrome nouveau, à un phénomène présentant de l'importance sur le plan politique ou médiatique ou encore à un risque de restriction des échanges commerciaux ou de voyages'26). Pour résumer ce sont les syndromes impliquant une urgence en santé publique internationale qui devront sur le champ être notifiés et qui devront être suivis d'un rapport sur la maladie incriminée dès que l'on disposera de l'information étiologique pertinente.

L'idée maîtresse de la révision est qu'il est plus efficace de lutter contre les maladies infectieuses au niveau mondial en suivant des stratégies de surveillance et d'intervention qui tireront parti des progrès techniques de communication, des méthodes scientifiques, ainsi que du diagnostic, du traitement des infections, plutôt qu'en appliquant des mesures de quarantaine ou autre à des sites éloignés de la source d'infection.

\section{4. l'intégration du RSI dans le droit français}

La France n'a pas formulé de réserve à l'égard du RSI. II est le fondement du droit positif français en matière de contrôle sanitaire depuis la loi

(24) V.R.A. Cash et V. Narasimhan, op. cit., v. p. 192.

(25) Cf. Sur le révision du RSI, The revision of IHR, Genève, OMC, 1998 (doc non publié G/SPS/ GEN $/ 59^{\circ}$. Révision du Règlement sanitaire international: rapport de situation, juillet 1999, Rel. Epidémiologique heb., 1999, 74 (30), pp. 252-253.

(26) R.A. Cash et V. Narasimhan, op. cit. 
n. 65-510 du $1^{\text {er }}$ juillet 1965 aux frontières terrestres, maritimes et aériennes. Aux termes de l'article L. 3115-1 du CSP le contrôle sanitaire aux frontières est régi par les dispositions des règlements sanitaires pris par l'OMS, les arrangements internationaux et les lois et les règlements nationaux. La première publication du RSI n. 2 révisé de 1969 remonte au décret $n .71-547$ du 15 juin 1971 (JO 9 juillet). Depuis le RSI révisé en 1971, puis en 1981, il a fallu attendre 1989 pour que le RSI révisé soit intégré en droit en droit français par le décret n. 89-38 du 24 janvier 1989 portant publication du règlement. (On notera que des textes nationaux organisant le contrôle sanitaire aux frontières s'appuient et précisent certaines des prescriptions du RSI).

Quid du problème de l'applicabilité directe et immédiate des normes issues du RSI en droit interne? Force est de constater qu'il est très difficile de trouver dans le contentieux relatif à un texte de l'OMS. Le seul exemple que l'on puisse trouver est un arrêt de la cour d'appel de Paris du 18 novembre 1967 ("époux pivert) qui affirme que le RSI ne peut s'appliquer que s'il est repris par un texte français"(27). Cette affaire concernait deux personnes rentrant de Tunisie en France, mais qui ne disposaient pas d'un certificat valable de vaccination contre la variole à leur arrivée en France et qui refusaient de se soumettre à la vaccination en dépit de l'intervention des services sanitaires de l'aéroport. Cette jurisprudence et plus que critiquable dans la mesure où le RSI est applicable de plein droit dans le droit interne. II faut en effet rappeler que l'article 22 de la constitution de l'OMS affirme très nettement qu'aucune intervention préalable n'est nécessaire pour l'entrée en vigueur du RSI. En effet la décision réglementaire est en elle-même un acte parfait du point de vue internationale.

\section{C-Perspectives et avenir du RSI du fait des problèmes liés aux notifica- tions de maladies et à leurs répercussions économiques et sociales ${ }^{(28)}$}

Les règles du RSI sont susceptibles parfois d'entrer en conflit avec d'autres règles contenues dans d'autres accords internationaux, notamment dans' le domaine commercial. Devant les peurs que des restrictions démesurées ne soient imposées aux échanges internationaux et aux voyages, le RSI et l'accord de l'OMC sur l'application des mesures sanitaires et phytosanitaires précisent les mesures à adopter. Le RSI dans sa forme actuelle énumère les mesures que les États peuvent prendre en indiquant les lignes directrices spécifiques pour les flambées de peste, choléra et fièvre: jaune. S'il précise les règles relatives à l'arrivée et au départ de navires et aéronefs, relatives au traitement des marchandises importées, ces règles ne sont toutefois pas assez détaillées pour faire face à des situations atypi-

(27) KHAN, PH. Journal de droit international, 1968, p. 728-729.

(28) Ce développement s'appuie sur les analyses et éléments d'information mentionnés dans l'article de R.A. Cash et V. Narasimhan, op. cit. 
ques. C'est la raison pour laquelle il a été proposé d'inclure dans le futur RSI révisé des annexes où l'on fixera des limites aux mesures à prendre. II est aussi proposé de créer des comités d'arbitrage qui règleront les différends relatifs aux pratiques commerciales après survenue d'une flambée de maladie. L'OMC quant à elle se sert de l'accord précité pour élaborer des règles de base indiquant quand les États peuvent appliquer ce qui serait normalement considéré comme des pratiques commerciales déloyales pour limiter l'entrée de marchandises ne répondant pas aux critère de sécurité. Si les dispositions de l'accord indiquent que les États ont le droit de protéger leurs nationaux, les États ne doivent cependant pas adopter des mesures extrêmes à moins que des faits scientifiques le justifie ${ }^{(29)}$. Ainsi que le relève certains auteurs, il y a de fortes probabilités que les États adoptent des mesures protectionnistes du fait du relâchement des restrictions commerciales de l'accord général sur les tarifs douaniers et le commerce ${ }^{(30)}$. Afin d'éviter que cela ne se réalise, les États sont autorisés en vertu des mesures sanitaires et phytosanitaires à soumettre leur politique contestées à un groupe d'expert pour examen et consultation. Pour faciliter les consultations ou les négociations ad hoc entre membres pour des questions sanitaires ou phytosanitaires, il est prévu également d'instituer un comité( ${ }^{(31)}$. On notera qu'en vue de l'harmonisation des lignes directrices nationales, l'OMC a reconnu que certains groupes tels que la commission du codex alimentarius ou l'Office international des épizooties élaborent des normes internationales sur le fondement desquelles des mesures appropriées peuvent être prises.

L'OMS et I'OMC entendent désormais collaborer dans le but d'éviter les conflits entre les règles du RSI et celles de l'accord sur l'application des mesures sanitaires et phytosanitaires. Le problème, ainsi que le rappelle R.A. Cash et V. Narasimhan, c'est "qu'il n'existe pas d'accord précis entre les deux organisations". C'est la raison pour laquelle on a avancé l'idée que l'OMS aide l'OMC à s'assurer que les Etats adoptent des mesures de santé publique exigées par une flambée de maladie.

Face à une flambée de maladie, la communauté internationale réagit fréquemment de manière disproportionnée et l'État touché qui notifie risque fortement de subir des pertes économiques majeures. Si la plupart des Etats adoptent une posture pertinente en respectant les lignes directrices de l'OMS et de l'OMC, il y a aussi un grand nombre d'États qui ne les respectent pas et qui de plus adoptent des mesures excessives sans rapport avec les informations scientifiques, le risque de maladie ou les actions préventives. Autrement dit, cela signifie que ces lignes directrices ne permettent pas de

(29) Information paper 1: a comparaison of the functions and requirements in public health and trade, OMS 1999 (doc. WHO/CDS/CSR/99.2), cité par R.A. Cash et V. Narasimhan, op. cit., p. 191.

(30) R.A. Cash et V. Narasimhan, op. cit., p. 191.

(31) Cf. Understanding the WTO Agreement on sanitary and Phytosanitary measures, Genève OMC 1998. 
protéger le pays qui notifie, et donc qu'il serait opportun que les organisations internationales révisent leur réglementation et qu'elles renforcent les lignes directrices internationales et les fassent respecter. Or les pouvoirs de l'OMS sont faibles pour faire appliquer le RSI, notamment en ce qui concerne les chapitres relatifs aux réactions internationales aux épidémies. Par conséquent, une stratégie juridique qui s'appuie principalement sur le RSI pour maîtriser les maladies émergentes est sans doute discutable selon nous...

En reprenant à notre compte l'analyse de $R$. A. Cash et $V$. Narasimhan ${ }^{(32)}$, la stratégie juridique doit intégrer deux données paradoxales, d'une part, "la mondialisation compromet la lutte contre les maladies au niveau national", et, d'autre part, devant la nécessité de solutions internationales, "le principe de souveraineté peut entraver la lutte contre les maladies au niveau mondial". II faut donc que les dispositifs juridiques qui devront être mis en place abordent véritablement les questions des ingérences dans les échanges commerciaux et touristiques.

Dans le cadre du processus de révision du RSI, il a été proposé que l'OMS puisse interdire aux États membres d'appliquer des mesures sanitaires extrêmes sans l'approbation d'un groupe d'experts. Toutefois, on doit relever ici l'existence de plusieurs inconnues: les États membres accepteront-ils que ce pouvoir soit donné à l'OMS et accepteront ils l'autorité de l'OMS? Un pays en développement s'il est injustement traité par d'autres Etats doit savoir qu'il dispose de voies de recours. II faudra par conséquent que les comités d'arbitrage proposés dans le RSI aient l'autorité pour régler des différends entre les États. Quant à l'OMC, elle peut, pour régler des différends entre États membres, s'appuyer sur l'accord SSP. Un État pourra ainsi obtenir réparation de préjudices causés par des pratiques commerciales déloyales durant une flambée de maladie. II faut donc que l'OMS et l'OMC développent une collaboration afin qu'un Etat qui aura notifié une flambée ne soit pas pénalisé injustement.

Pour conclure, sur cette dimension si particulière de la législation OMS que constitue le RSI, il apparaît que le système de surveillance contre les maladies transmissibles, dans le cadre duquel le RSI va être révisé, ne pourra être efficace que si l'OMS en partenariat avec l'OMC réfléchit et développe de nouveaux moyens pour protéger les intérêts des États procédant à des notifications. En effet, à défaut d'action de ce type, il est fort probable que les États, en particulier les plus pauvres continueront d'occulter les épidémies. II faudra notamment que l'on développe au plan international toute une politique d'accompagnement d'aides économiques afin d'inciter ces États à notifier les flambée de maladie. Il en va de la sécurité sanitaire du monde.

(32) R.A. Cash et V. Narasimhan, op. cit., p. 196. 